Commentary

\title{
On applying the matching law to between-subject data
}

\author{
Pier-Olivier Caron* \\ Laboratoire des Sciences Appliquées du Comportement, Département de Psychologie, Université du Québec à Montréal, Montréal, QC, Canada
}

\section{A R T I C L E I N F O}

\section{Article history:}

Received 26 October 2012

Initial acceptance 7 December 2012

Final acceptance 14 January 2013

Available online 28 February 2013

MS. number: AS-12-00812R

\section{Keywords:}

between-subject variance

choice

matching law

pooled data

within-level variance

within-subject variance

The matching law is a descriptive mathematical model that conceptualizes an organism's response rates as a function of relative rates of reinforcement (Herrnstein 1961). This relation is expressed by equation (1):

$B 1 / B 2=R 1 / R 2$

where $B$ s represent rates of behaviour and $R$ s represent reinforcer rates. However, extensive research has confirmed that organisms' behaviour systematically deviates from predictions of equation (1) (Baum 1974, 1979, 1983; Wearden \& Burgess 1982; Davison \& McCarthy 1988; McDowell 2012). The power function version, known as the generalized matching law (Baum 1974), provides better descriptions of animals' and humans' choices in concurrent schedules and is represented logarithmically by equation (2):

$\log (B 1 / B 2)=a \log (R 1 / R 2)+\log c$

where $B s$ and $R s$ are the same as in equation (1), $a$ is referred to as sensitivity and represents the organism's adjustment to the contingencies, and $c$ is called the bias parameter and represents the organism's preference when choice is asymmetrical. Note that equation (2) reduces to equation ( 1 ) when $a=c=1$, and is usually

\footnotetext{
* Correspondence: P.-O. Caron, Université du Québec à Montréal, Département de Psychologie, C.P. 8888, succursale Centre-ville, Montréal, QC H3C 3P8, Canada.

E-mail address: pocaron19@gmail.com.
}

called strict matching. Furthermore, most studies have found that the sensitivity value varies around 0.8 , which is referred to as undermatching.

Herrnstein (1961) developed the matching law to describe individual choices. A misunderstanding of this fundamental assumption has led several authors (i.e. Schroeder \& Holland 1969; Conger \& Killeen 1974; Schmitt 1974; Vollmer \& Bourret 2000; Borrero \& Vollmer 2002; Alferink et al. 2009; McDowell \& Caron $2010 a, b)$ to conduct their analyses incorrectly. For instance, they used a small number of levels of the independent variable and pooled their subjects' data, which combined idiosyncratic dependent variables into a single analysis and did not account for within-subject and within-level variances. At best, betweensubject data will estimate an inaccurate model with erroneous parameter values and, at worst, will violate several statistical assumptions and lead to uninterpretable results. The purpose of the current study is to prevent future misunderstanding by clarifying these errors.

\section{Pooling Different Variables}

Statistically, the dependent variable must be the same through all levels of the independent variable. Applied to the matching law, this means that the response ratio must remain the same at all levels of the reinforcer ratios. Therefore, between-subject analyses must rely on the same responses for every subject. However, if the subjects had different target behaviours, then their log response 
ratios would be different and thus pooling them would combine nonequivalent dependent variables into a single analysis, which is statistically inappropriate.

For example, a pigeon in a concurrent variable-interval schedule of reinforcement shows strict matching (Herrnstein 1961) while another pigeon in a concurrent key-pecking/treadle-pressing schedule of reinforcement shows undermatching and a strong bias for treadle pressing (McSweeney 1978). The response ratio of the first pigeon is represented by log (keypeck 1 /keypeck 2 ), and the response ratio of the second pigeon is represented by $\log$ (treadle - press/keypeck). In this case, a between-subject analysis is inappropriate because both subjects imply different dependent variables.

An example of this issue appears in the work of St Peter et al. (2005). They observed several problem behaviours functionally and topographically specific to three individuals with varying degrees of developmental disabilities. They investigated whether the generalized matching law adequately describes these problem behaviours. At the group level, subjects slightly deviated from strict matching $(a=1.04)$. However, within-subject matching showed a wide range of sensitivity values $(0.76,0.76$ and 1.11$)$, bias values $(0.16,0.33$ and 0.07$)$ and explained variance values $(0.92,0.83$ and $0.69)$. Note that because the logarithm of zero is undefined, a substantial number of data points were removed from these analyses. Still, between-subject data are likely to estimate inaccurate parameter values because the analysis combines different dependent variables that are supposed to be specific to each subject.

\section{Individual Choice Behaviour}

At the group level, the covariance of $B$ and $R$ ratios depends on between-subject variances but also on within-subject variances and the within-level variance of the independent variable. It is unlikely that a subject's overall ratio, calculated by averaging all ratios of a subject for a between-subject analysis, accounts for these three levels of variance. Therefore, regressions on these overall ratios increase the possibilities of error and lead to a betweensubject matching that inaccurately represents within-subject matching relations.

A hypothetical example will illustrate this problem. Figure 1 shows the slope, intercept and explained variance for six subjects. At the within-subject level, each subject shows a different matching relation. For instance, subjects 1 and 5 do not match, subject 2 overmatches $(a>1)$, subject 3 antimatches $(a<0)$ with an important bias, subject 4 strongly undermatches and subject 6 undermatches. Every subject shows an idiosyncratic matching relation. However, the group-level results, presented in Fig. 2, show that subjects slightly deviate from strict matching and have a negligible bias. Obviously, group-level results are unrepresentative of within-subject matching even if subjects' data are averaged or not. In fact, no subject showed a similar matching relation.

Even though this example relies on hypothetical data, similar issues appear in the literature. For instance, Borrero et al. (2007) investigated whether the generalized matching law describes social interactions among undergraduate students. When subjects' data were pooled, they found through nine analyses that sensitivity
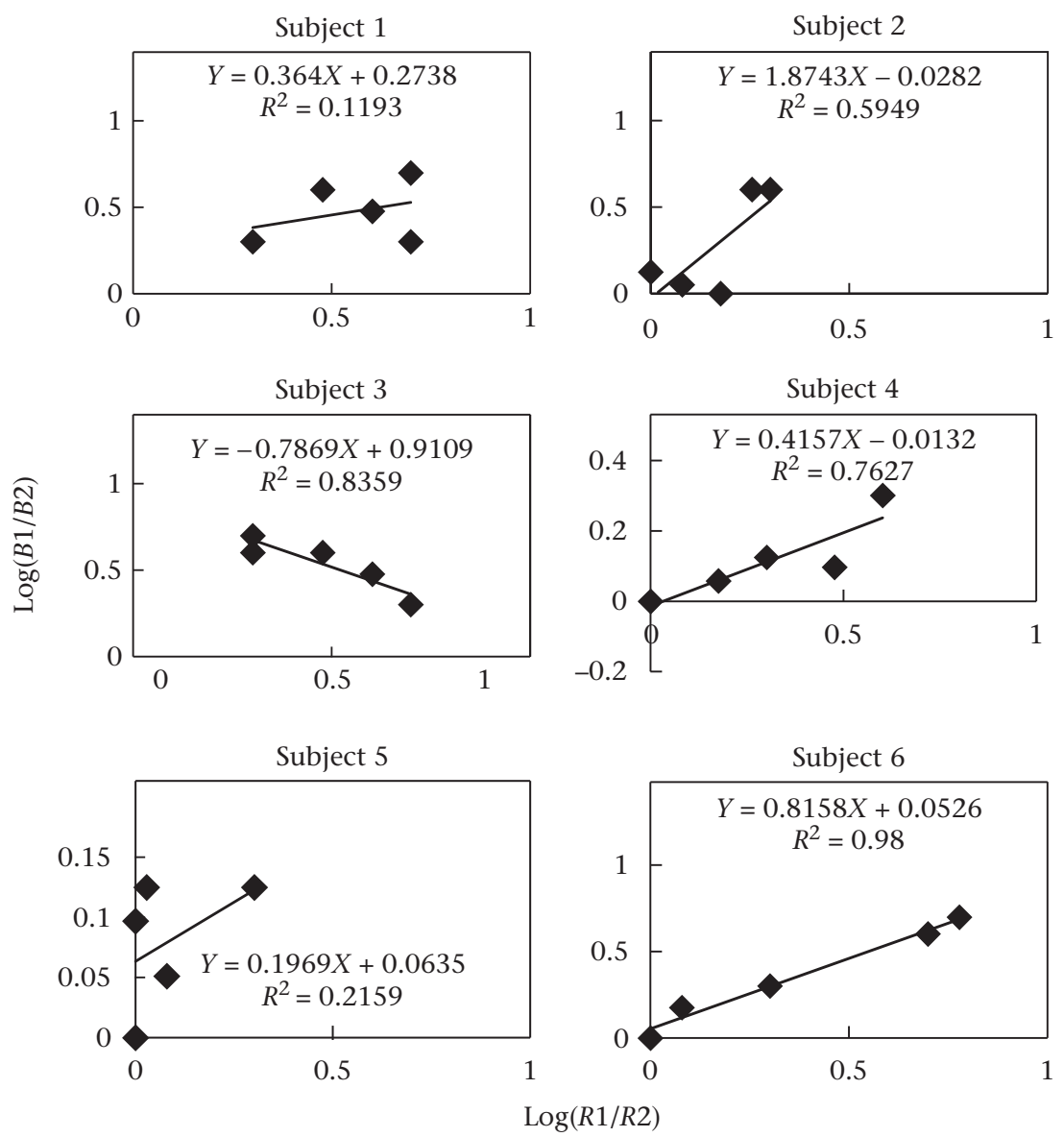

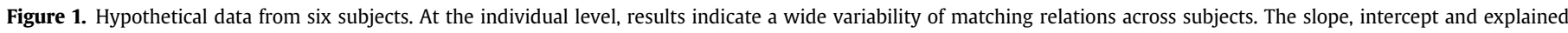
variance are shown for each subject. No subject shares similar parameter values. 

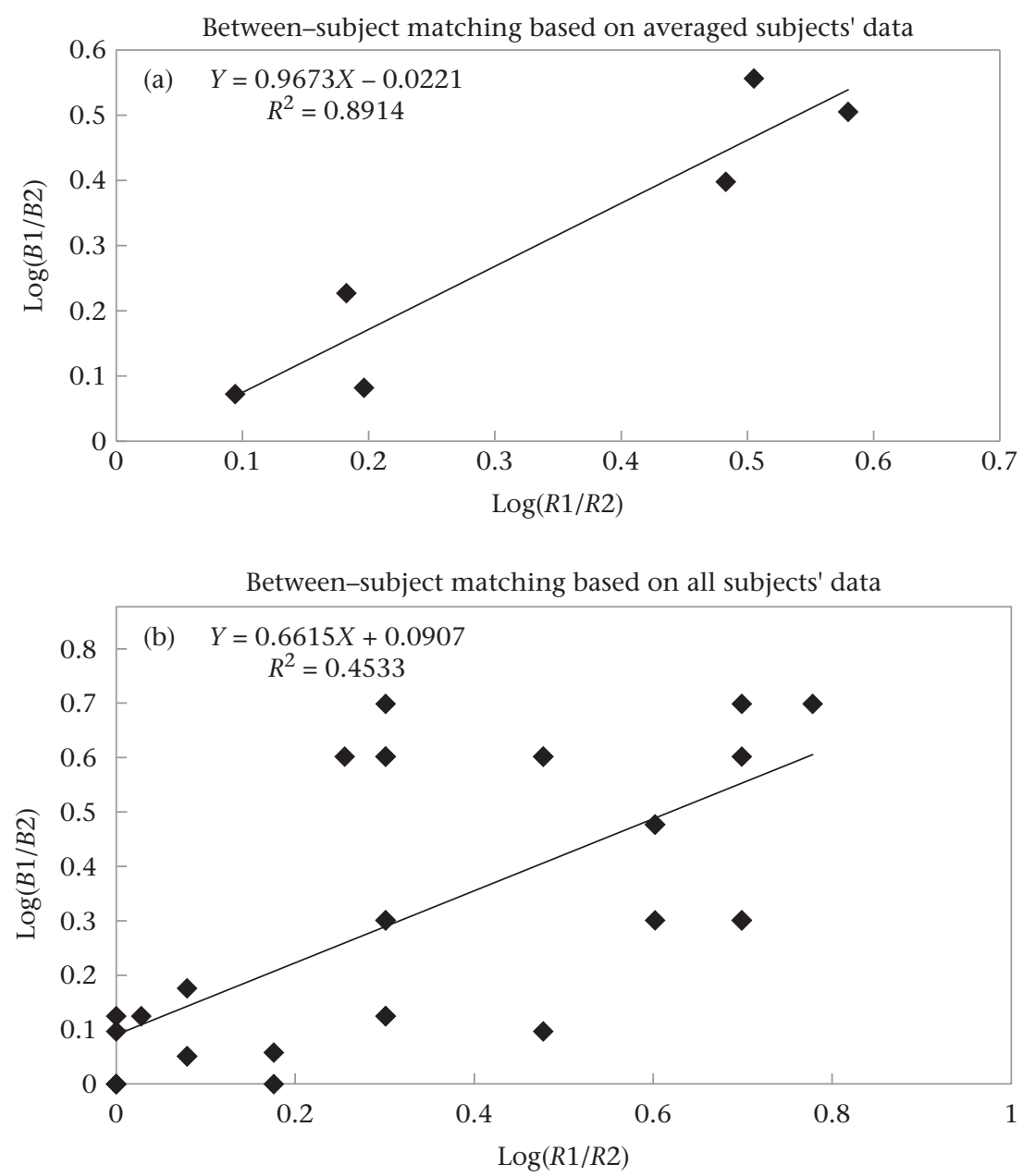

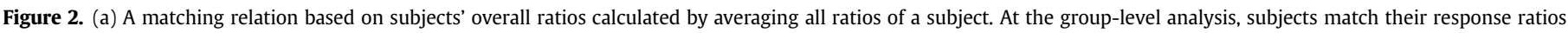

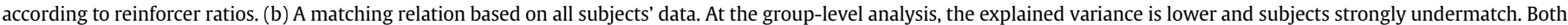
analyses show an unrepresentative description of within-subject matching relations.

values varied from 0.50 to 1.25 (mean $=0.70$ ), bias values varied from -0.37 to 0.28 (mean $=0.05)$ and explained variance values varied from $44 \%$ to $70 \%$ (mean $=54 \%$ ). Noteworthy, there was only one case of overmatching and two cases of negative biases. However, within-subject analyses showed a wider range of variability. According to time or response allocation, sensitivity values varied from 0.03 to 1.84 (mean $=0.87$ ), bias values varied from -0.65 to 0.29 (mean $=-0.100)$ and explained variance values varied from $0.10 \%$ to $100 \%$ (mean $=72 \%$ ). Altogether, these results are similar to the hypothetical example and indicate that between-subject matching does not account for the within-subject variance and the within-level variance of the independent variable.

\section{Small Number of Ratios}

To be valid, the generalized matching law, as in any regression, requires a substantial number of controlled levels of the independent variable. Moreover, the within-level variance in the dependent variable has to be less than the across-level variance. Otherwise, it may overwhelm the across-level variance and lead to an inaccurate model. Such a situation gets worse when response rates become so low that every response is reinforced. Any variation of the response ratio drives the reinforcer ratio and increases the within-level variance. In other words, the independent variable becomes the dependent variable and vice versa. A concurrent variable-interval schedule allows a certain amount of drive that is negligible when response rates are much higher than reinforcer rates. However, when response rates become excessively low and contingencies of reinforcement are not controlled for, which is common in applied settings, matching relations become spurious.

A case of excessively low response rates possibly appeared in the study by Borrero et al. (2007) because (1) they tested two reinforcer ratios, a concurrent variable-interval $(30 \mathrm{~s}, 120 \mathrm{~s})$ schedule and its reciprocal, (2) the session lasted 20-30 min, (3) the duration of an instance of the response could be longer than the duration specified by the concurrent schedule and (4) the reinforcers were always given at the end of the response. These conditions increased the across-level variance because subjects were allowed to respond at an extremely low rate and thus were reinforced according to the same rate. In fact, both levels of the independent variable were graphically indistinguishable from each other. Even at an individual level, matching relations were spurious.

\section{Conclusion}

The purpose of the current study is to show common misconceptions about the matching law and to prevent these mistakes in future studies. These misconceptions may arise because of the high availability of between-subject data compared with that of within-subject data and the ease of conducting inappropriate 
statistical analyses. Moreover, seminal papers have not always put emphasis on the variable nature or the importance of withinsubject analyses. However, if researchers are trying to discover the quantitative law underlying choice, they must bear in mind that, until proven otherwise, the generalized matching law accounts for individual behaviour.

I thank Katia Lamer and an anonymous referee for their helpful comments on an earlier draft of this paper.

\section{References}

Alferink, L. A., Critchfield, T. S., Hitt, J. L. \& Higgins, W. J. 2009. Generality of the matching law as a descriptor of shot selection in basketball. Journal of Applied Behavior Analysis, 42, 595-608, http://dx.doi.org/10.1901/jaba.2009.595-608.

Baum, W. M. 1974. On two types of deviation from the matching law: bias and undermatching. Journal of the Experimental Analysis of Behavior, 22, 231-242. http://dx.doi.org/10.1901/jeab.1974.22-231.

Baum, W. M. 1979. Matching, undermatching, and overmatching in studies of choice. Journal of the Experimental Analysis of Behavior, 32, 269-281, http:// dx.doi.org/10.1901/jeab.1979.32-269.

Baum, W. M. 1983. Matching, statistics, and common sense. Journal of the Experimental Analysis of Behavior, 39, 499-501, http://dx.doi.org/10.1901/ jeab.1983.39-499.

Borrero, J. C. \& Vollmer, T. R. 2002. An application of the matching law to severe problem behavior. Journal of Applied Behavior Analysis, 35, 13-27, http:// dx.doi.org/10.1901/jaba.2005.172-04.

Borrero, J. C., Crisolo, S. S., Tu, Q., Rieland, W. A., Ross, N. A., Francisco, M. T. \& Yamamoto, K. Y. 2007. An application of the matching law to social dynamics. Journal of Applied Behavior Analysis, 40, 589-601, http://dx.doi.org/10.1901/ 2007.589-601.

Conger, R. \& Killeen, P. 1974. Use of concurrent operants in small group research: a demonstration. Pacific Sociological Review, 17, 399-416.
Davison, M. \& McCarthy, D. 1988. The Matching Law: a Research Review. Hillsdale, New Jersey: L. Erlbaum.

Herrnstein, R. J. 1961. Relative and absolute strength of response as a function of frequency of reinforcement. Journal of the Experimental Analysis of Behavior, 4, 267-272, http://dx.doi.org/10.1901/jeab.1961.4-267.

McDowell, J. J. 2012. On the theoretical and empirical status of the matching law and matching theory. Psychological Bulletin, published online 3 September 2012, http://dx.doi.org/10.1037/a0029924.

McDowell, J. J. \& Caron, M. L. 2010a. Bias and undermatching in delinquent boys' verbal behavior as a function of their level of deviance. Journal of the Experimental Analysis of Behavior, 93, 471-483, http://dx.doi.org/10.1901/jeab.2010. 93.471.

McDowell, J. J. \& Caron, M. L. 2010b. Matching in an undisturbed natural human environment. Journal of the Experimental Analysis of Behavior, 93, 415-433, http://dx.doi.org/10.1901/jeab.2010.93-415.

McSweeney, F. K. 1978. Prediction of concurrent keypeck treadle-press responding from simple schedule performance. Animal Learning and Behavior, 6, 444-450, http://dx.doi.org/10.3758/bf03209642.

St Peter, C. C., Vollmer, T. R., Bourret, J. C., Borrero, C. S. W., Sloman, K. N. \& Rapp, J. T. 2005. On the role of attention in naturally occurring matching relations. Journal of Applied Behavior Analysis, 38, 429-443, http://dx.doi.org/ 10.1901/jaba.2005.172-04.

Schmitt, D. R. 1974. Effects of reinforcement rate and reinforcer magnitude on choice behavior of humans. Journal of the Experimental Analysis of Behavior, 21, 409-419, http://dx.doi.org/10.1901/jeab.1974.21-409.

Schroeder, S. R. \& Holland, J. G. 1969. Reinforcement of eye movement with concurrent schedules. Journal of the Experimental Analysis of Behavior, 12, 897903, http://dx.doi.org/10.1901/jeab.1969.12-897.

Vollmer, T. R. \& Bourret, J. 2000. An application of the matching law to evaluate the allocation of two- and three-point shots by college basketball players. Journal of Applied Behavior Analysis, 33, 137-150, http://dx.doi.org/10.1901/ jaba.2000.33-137.

Wearden, J. H. \& Burgess, I. S. 1982. Matching since Baum (1979). Journal of the Experimental Analysis of Behavior, 38, 339-348, http://dx.doi.org/10.1901/ jeab.1982.38-339. 